\title{
Evaluation of safety barriers deduced from the HAZOP study of fired heater F201-101, ADRAR refinery, Algeria using ETA method.
}

\author{
BATOUT Naoual $^{(1)}$, BENDIB Riad $^{(2)}$, ZENNIR Youcef $^{(3)}$ \\ (1) Department of petrochemical and process engineering. University of Skikda, Skikda, Algeria \\ (2) Department of petrochemical and process engineering. University of Skikda, Skikda, Algeria \\ ${ }^{(3)}$ Department of petrochemical and process engineering. University of Skikda, Skikda, Algeria \\ ${ }^{(1)}$ batoutnaoual@yahoo.fr,${ }^{(2)}$ r.bendib@univ-skikda.dz, ${ }^{(3)}$ y.zennir@univ-skikda.dz
}

\begin{abstract}
This paper described the method of event tree analysis that is commonly used to identify, characterize and estimate the risk. Quantitative estimates for probability of breach or failure and the resulting consequences can be obtained using event trees. Qualitative depictions of potential failure modes and consequences can also be developed using event trees. An event tree analysis (ETA) is an inductive procedure that shows all possible outcomes resulting from an accidental (initiating) event. An event tree consists of a sequence of interconnected nodes and branches. Each node defines a random variable that represents an uncertain event or state of nature. Branches originating from a node represent each of branches to represent the likelihood for each event or condition. These probabilities are conditional on the occurrence of the preceding events to the left in the tree.

Our work includes a HAZOP study to determine the necessary safety barriers as a first step. And as a second step is their evaluation using ETA method of fired heater F201-101, ADRAR refinery, Algeria. This particular method is well suited to estimating the risk stemming from process plant failure. Neither the initiators of industrial accidents nor the layers of protection that prevent them are typically complex, that is, they do not usually require analysis by redundant systems or the time for on-line repair. Thus, they can be accurately characterized with the probability multiplication methods that from the basis of event tree analysis.
\end{abstract}

Keywords: Safety, probabilistic risk assessment, outcome frequency, event tree analysis

\section{INTRODUCTION}

Safety critical systems are extensively used in many industries, including the aerospace, automotive, medical, and energy sectors. Systems that fall into this category range from airbags in cars to propulsion systems on spacecraft; however, they all share a common property, their failure has the potential to cause catastrophic effects on human life as well as the environment. For this reason, it is expected that safety critical systems process a high level of safety and reliability. While safety is the avoidance of harm to people and the environment, reliability is the ability to perform the intended function uninterrupted by failure, which is often a precondition for safety. Both properties are crucial, and as systems become more complex, their prediction via analysis plays a vital role in the successful design and development of the system; at the same time, with increasing complexity analyses become increasingly difficult [1][2][3].

Different probabilistic risk assessment (PRA) methods have been used to evaluate system safety and reliability [2].

ETA is one of the most widely used PRA approaches to estimate system safety and reliability.

Event tree analysis is the most straightforward of the common fault propagation modeling techniques. This paper describes how to use event tree analysis to both determine the frequencies of events and to average consequences where multiple outcomes are possible from a single incident. Both the physical appearance of the tree and the logical relationship between the events are explained. The basic tree begins with an initiating event that starts one or more chains of intermediate events leading to their various final outcomes. The outcomes are then at the end of each branch, and their frequency or probability is calculated by following the sequence set out by the branched paths lead from the mitigating event [4].

Solving for event tree outcome frequencies or probabilities is an exercise in probability math. Each individual outcome's probability or frequency is a function of the likelihood of 
each of the events along the path from the initiating event to that outcome.

When using event trees to average outcome consequences, you must consider the probability acts to weight or adjust the different outcomes, which you then total to get an overall result [3][5].

\section{EVENT TREE ANALYSIS}

A typical event tree is shown in "Fig. 1". An event tree begins with a single initiating event, which is usually an action or a failure of a piece of equipment that starts the chain of events leading to one of several outcomes.

The event tree's branches determine the different event sequence paths to the various outcomes. Each branch consists of a set of events that can occur in the chain leading to the final outcomes. Each branch associates a probability of occurrence with each possible event in the branch set [5].

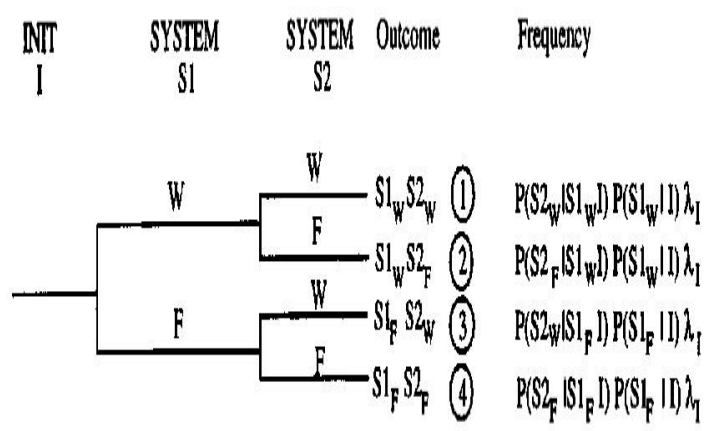

Fig. 1 Simple event tree structure.

\section{STEPS IN CONSTRUCTION EVENT TREE}

$>$ Identify and define a relevant accidental (initial) event that may give rise to unwanted consequences.

$>$ Identify the barriers that are designed to deal with the accidental event.

$>$ Construct the event tree.

$>$ Describe the (potential) resulting accident sequences.

$>$ Determine the frequency of the accidental event and the (conditional) probabilities of the branches in the event tree.

$>$ Calculate the probabilities/frequencies for the identified consequences (outcomes).

$>$ Compile and present the results from the analysis [6].

\section{INITIATING EVENTS}

An initiating event starts the chain of events that can lead to the unwanted accident if one of the protection layers does not prevent it from propagating.

Any number of things can initiate an unwanted accident, from the failure of a piece of process equipment or instrumentation.

Initiating events are usually quantified by their frequency of occurrence. Sometimes, event trees are completely described using probability; in these cases the initiating event will also be expressed as a probability [3] [15]

\section{BARRIERS}

$\checkmark$ Most well designed systems have one or more barriers to stop or reduce the consequences of potential accidental events.

$\checkmark$ Barriers may be technical and/or administrative (organizational).

$\checkmark$ The barriers that are relevant for a specific accidental event should be listed in the sequence they will be activated [7].

Examples include:

- Automatic detection systems (e.g.; fire detection)

- Automatic safety systems (e.g.; fire extinguishing)

- Alarms warning personnel/operators

- Procedures and operator actions

- Mitigating barriers.

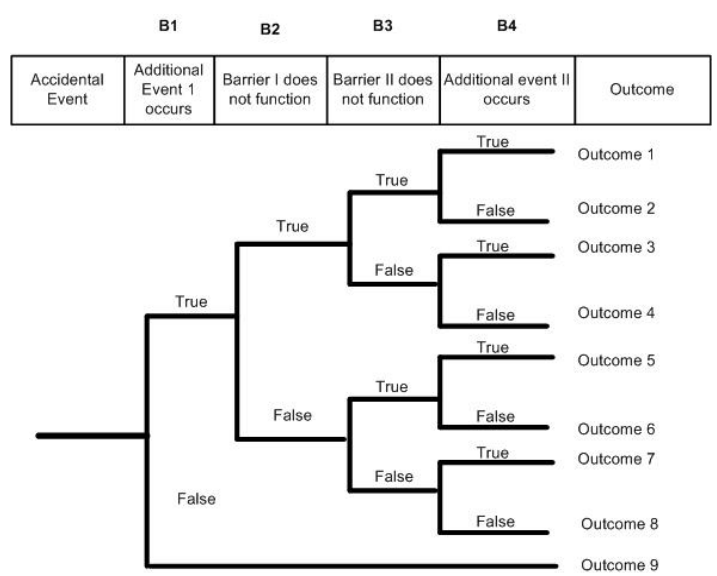

Fig. 2 Generic example.

\section{BRANCHES}

The branches of an event tree are groups of events where different outcomes are possible depending on which event or events of the set are true. The intermediate outcome selected from each set of events that make up each branch determines the overall outcome.

Branches of event trees are usually complementary events [15]. 


\section{FREQUENCIES OF OUTCOMES}

Let $\lambda$ denotes the frequency of the accidental (initiating) event. Let $\operatorname{Pr}(\mathrm{Bi})$ denotes the probability of event $B(i)$.

When we know that the accidental even has occurred, the probability of "Outcome 1 " is:

$\operatorname{Pr}($ Outcome $1 /$ Accidental event $)=\operatorname{Pr}(B 1 \cap$ $\mathrm{B} 2 \cap \mathrm{B} 3 \cap \mathrm{B} 4)=\operatorname{Pr}(\mathrm{B} 1)^{\star} \operatorname{Pr}(\mathrm{B} 2 / \mathrm{B} 1)^{\star} \operatorname{Pr}(\mathrm{B} 3 / \mathrm{B} 1$ $\cap \mathrm{B} 2)^{\star} \operatorname{Pr}(\mathrm{B} 4 / \mathrm{B} 1 \cap \mathrm{B} 2 \cap \mathrm{B} 3)$

Note that all the probabilities are conditional given the result of the process until "barrier" $i$ is reached.

The frequency of "Outcome 1" $f$ is:

$$
\mathbf{f}=\lambda^{\star} \operatorname{Pr}(\mathrm{B} 1 \cap \mathrm{B} 2 \cap \mathrm{B} 3 \cap \mathrm{B} 4)
$$

The frequencies of the other outcomes are determined in a similar way.

\section{GENERAL RISK IDENTIFICATION AND HAZARD ANALYSIS}

There are several different accepted methods for identifying process risks and analyzing hazards. Most of them take the form of a proactive study called a process hazard analysis (PHA). Most methods of PHA consist of a structured brainstorming exercise in which a team of experts systematically reviews sections of a process to identify possible hazards. The PHA team also lists the events that can cause accidents, the potential outcome of these accidents, and the safeguards in place to prevent the accidents. Finally, the PHA recommends other measures the organization should implement to reduce process risk.

A wide variety of PHA methods are used in process plants. The type used depends on the complexity of the process under study, the amount of experience that an organization has with the process, and whether the plant is new or undergoing a review. The most popular PHA method is the hazards and operability study (HAZOP) [11][15].

\section{HAZARDOUS OPERABILITY STUDIES (HAZOP)}

A HAZOP study is a highly disciplined procedure meant to identify how a process may deviate from its design intent. It is defined as the application of a formal, systematic critical examination of the process and the engineering intentions of new or existing facilities to assess the potential for malfunctioning of individual pieces of equipment, and the consequential effects on the facility as a whole.
Its success lies in the strength of that methodology in following a system's Process Flow Diagrams (PFDs) and Piping and Instrumentation Diagrams (P\&IDs), breaking the design into manageable sections with definite boundaries called nodes, so ensuring the analysis of each piece of equipment in the process.

According to 'Keltz' it is the recommended method for identifying hazards and problems which prevent efficient operation" [8], [9].

Executing the method relies on using guidewords (such as, no, more, less) combined with process parameters (e.g., temperature, flow, pressure) that aim to reveal deviations (such as less flow, more temperature) of the process intention or normal operation. This procedure is applied in a particular node, viz., as a part of the system characterized for a nominal intention of the operative parameters. Having determined the deviations, the expert team explores their feasible causes and their possible consequences. For every pair of cause-consequence, safeguards must be identified that could prevent, detect, control, or mitigate the hazardous situation.

Finally, if the safeguards are insufficient to solve the problem, offering recommendations must be considered. The HAZOP procedure was described in many books and references [10], [11], [12], [13].

\section{CASE STUDY}

In this paper, the fired heater F201-101 of crude distillation unit of ADRAR refinery, located in the south of Algeria is taken as a case study.

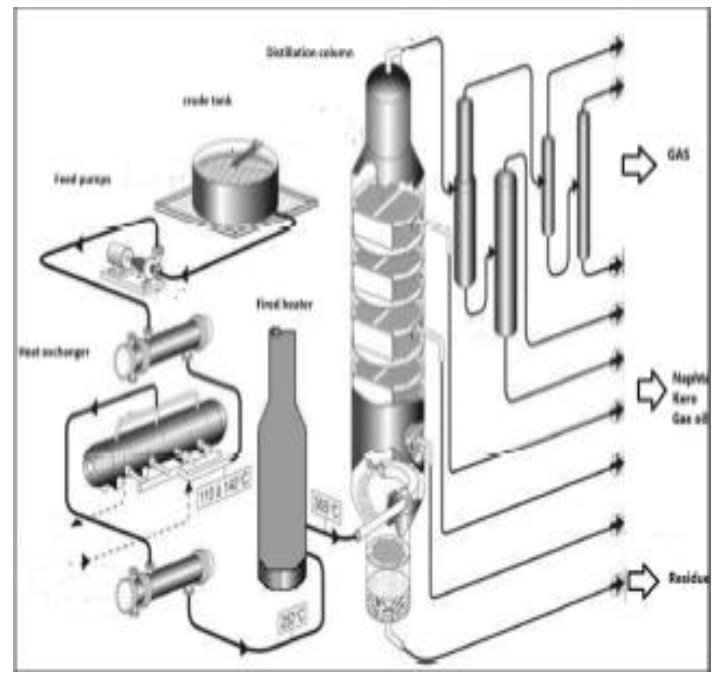

Fig. 3 Process diagram for crude distillation unit. 
Following the same of CDUs in different refineries in the world, the crude is first stored the storage tanks and using the feed pumps is loaded to distillation tower for separation before feeding the crude to distillation column its temperature should be augmented to reach $365^{\circ} \mathrm{C}$, this is done in two steps, the first called preheating through a series of heat exchangers, the second is the heating step where the fired heater F201-101 is used to rise the temperature to approximately $360^{\circ} \mathrm{C}$.

Generally the parameters should be controlled in any fired heater are:

* The product flow in each passes of the heater.

* The temperature for both product and tube inside.

* The pressure: fuel gas pressure in both burner and pilot gas lines also the pressure inside the combustion room of the heater.

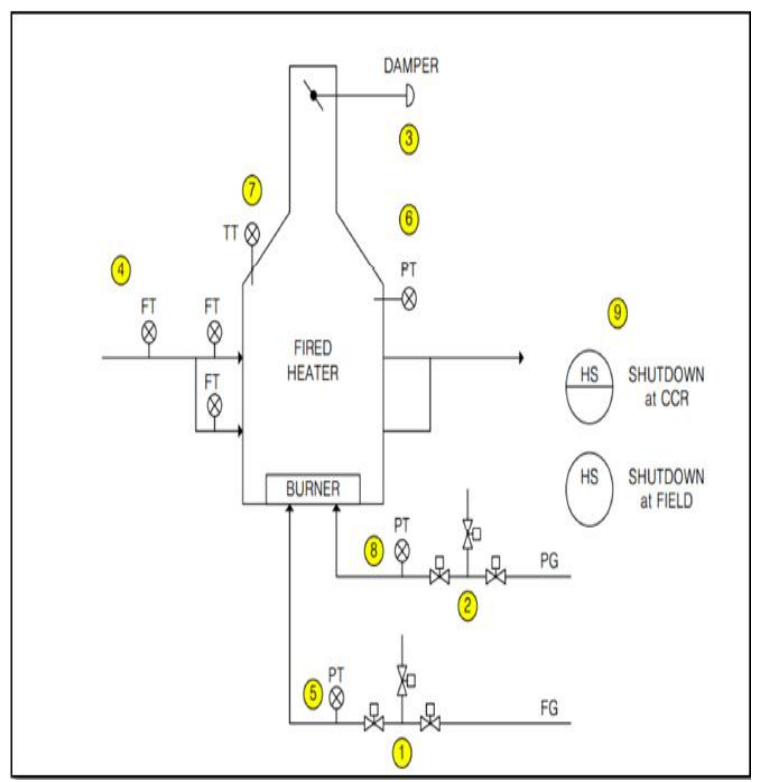

Fig. 4 The controlled parameters.

With:

FT, PT, TT are flow transmitters, pressure transmitters and temperature transmitters.

By studying all relevant accidental events that have been identified by a preliminary hazard analysis, a HAZOP, The Table 1 summarized these scenarios. The ETA can be used to identify all potential accident scenarios and sequences in a complex system.
Table 1 Scenarios

\begin{tabular}{|c|c|}
\hline Deviation & Scenario \\
\hline $\begin{array}{l}\text { Low / low } \\
\text { pressure in the } \\
\text { fuel gas and } \\
\text { pilot gas lines. }\end{array}$ & $\begin{array}{l}\text { Burner can extinguish at low } \\
\text { fuel gas pressure and } \\
\text { possible flammable material } \\
\text { accumulation inside the } \\
\text { heater. There is a possibility } \\
\text { of explosion during heater } \\
\text { restart-up. The existing } \\
\text { protection to avoid this } \\
\text { scenario is explosion } \\
\text { windows of the heater. }\end{array}$ \\
\hline $\begin{array}{l}\text { No or low flow of } \\
\text { the crude in } \\
\text { each pass }\end{array}$ & $\begin{array}{l}\text { No/low flow of the product in } \\
\text { each pass will lead to } \\
\text { increase the skin } \\
\text { temperature of the } \\
\text { corresponding heater tube } \\
\text { which will lead to tube } \\
\text { damage. Fire and explosion } \\
\text { is expected. }\end{array}$ \\
\hline $\begin{array}{l}\text { High/High } \\
\text { temperature in } \\
\text { the heater box }\end{array}$ & $\begin{array}{l}\text { Prolonged exposure to high } \\
\text { temperature may cause } \\
\text { tube failure which will lead } \\
\text { to explosion and unit } \\
\text { shutdown. } \\
\text { High temperature of the } \\
\text { crude may lead to } \\
\text { perturbation of distillation } \\
\text { column operation, and it } \\
\text { may cause harm for the } \\
\text { column internal in future. }\end{array}$ \\
\hline
\end{tabular}

Following the definition described in this work the evennt trees for the fired heater are showing in these figures:

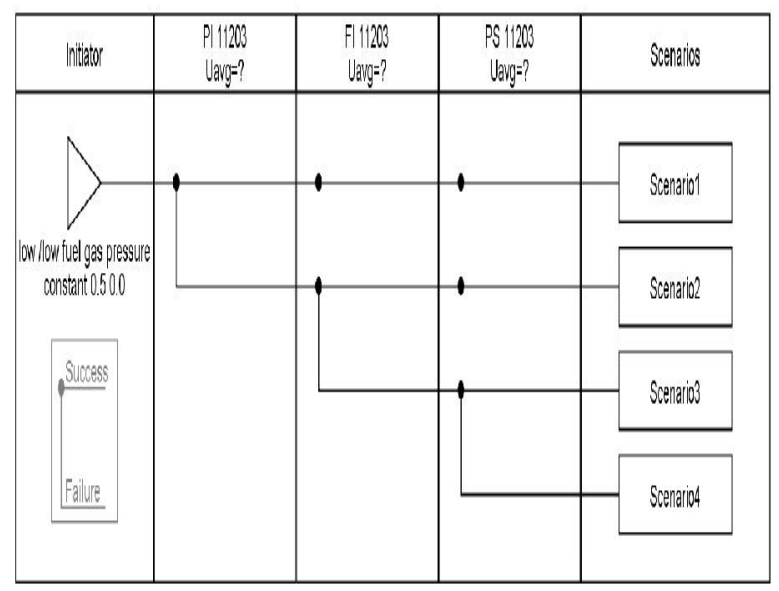

Fig. 5 ETA of the event 1. 


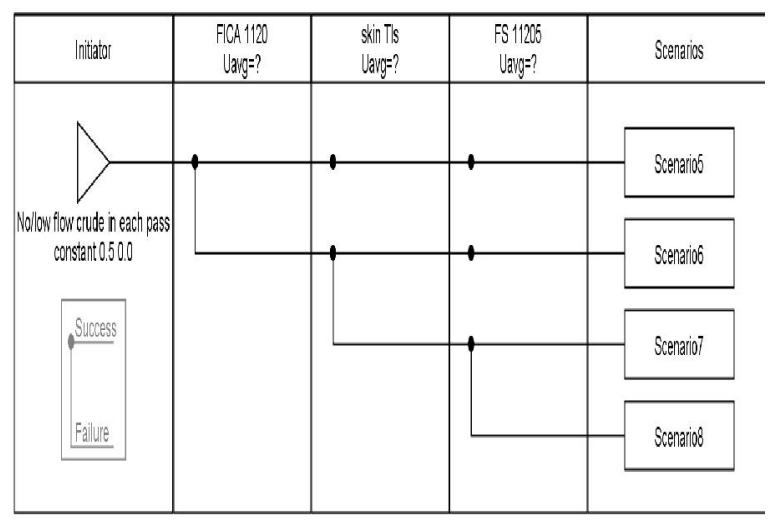

Fig. 6 ETA of the event 2.

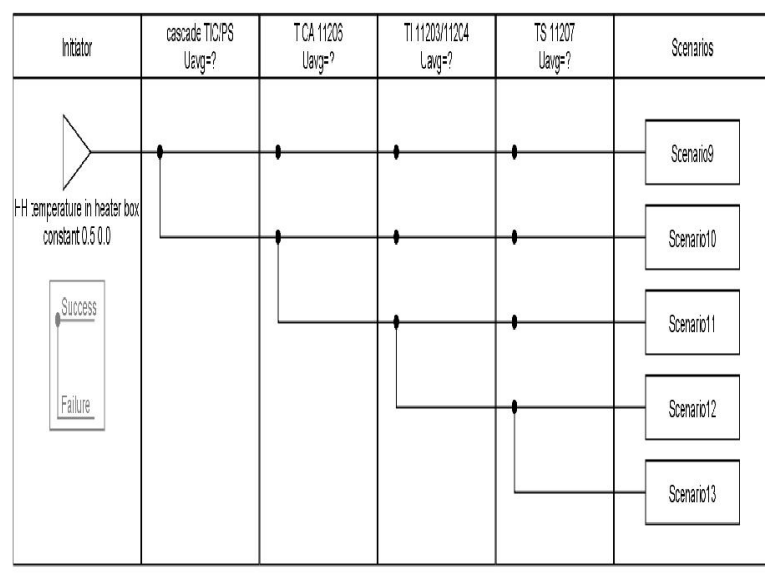

Fig. 7 ETA of the event 3.

With:

* FI 11203: Flow indication in DCS.

* PS 11203: Pressure switch exists to shut down the fired heater in case where there is no/less flow of fuel gas to heater

* PI 11203: Pressure indication.

* TI 11203/11204: Temperature indications in DCS.

* TICA 11206: temperature indication in DCS..

* TS 11207: Interlock to shut down the heater in case of high/high teperature.

* FICA: Flow indication in DCS.

* FS 11205: Interlock to shut down the heater in case where low/less flow.

The PFD in the Table 2 [14] is used to calculate the corresponding frequencies of each event and probability is calculated by following the sequence set out:

$\mathrm{f} 1=\lambda_{1}$ * PFD1 * PFD2 * PFD3 $=0.0498$

$\mathrm{f} 2=\lambda_{2}$ * PFD3 *2(PFD7) * PFD5 $=0.1148$ $\mathrm{f} 3=\lambda_{3}{ }^{*}(\text { PFD6 }+ \text { PFD3 })^{\star}$ PFD6 ${ }^{\star}$ PFD7 ${ }^{\star}$ PFD8 $=0.0789$
Table 2 PFD SIFs's

\begin{tabular}{|l|l|}
\hline SIFs & PFD values \\
\hline PI 11203 & PFD1 $=3.38 E-3$ \\
\hline FI 11203 & PFD2 $=6.7 \mathrm{E}-3$ \\
\hline PS 11203 & PFD3 $=4.4 \mathrm{E}-3$ \\
\hline FICA 11201 & PFD3 $=6.72 \mathrm{E}-3$ \\
\hline SKIN TI & PFD4 $=2.54 \mathrm{E}-3$ \\
\hline FS11205 & PFD5 $=6.73 \mathrm{E}-3$ \\
\hline TICA 11206 & PFD6 $=2.56 \mathrm{E}-3$ \\
\hline TI 11203/11204 & PFD7 $=2.54 \mathrm{E}-3$ \\
\hline TS 11207 & PFD8 $=3.5 \mathrm{E}-3$ \\
\hline
\end{tabular}

To evaluate this safety barriers we has classified the worst outcome of each accidental event using the risk matrix $4 \times 4$ with:

- four event frequency: very probable, probable, unlikely, extremely unlikely.

- Four sevrity of damage: low, average, high, catastrophic.

- Three risk level: 1, 2, 3 represent respectively undesirable (unwanted) risk, improvable risk and acceptable risk.

\begin{tabular}{|l|c|c|c|c|}
\cline { 2 - 5 } \multicolumn{1}{c|}{} & \multicolumn{4}{c|}{$\begin{array}{l}1=\text { Risk level } \\
\text { 1= improvable (unwanted) } \\
3=\text { acceptable }\end{array}$} \\
\hline $\begin{array}{l}\text { Very } \\
\text { probable }>1 \\
0^{-1}\end{array}$ & 3 & 2 & 1 & 1 \\
\hline $\begin{array}{l}\text { Probable } \\
10^{-3} \text { à10 }\end{array}$ & 3 & 3 & 2 & 1 \\
\hline $\begin{array}{l}\text { Unlikely } 10^{-5} \\
\text { à10 }\end{array}$ & 3 & 3 & 3 & 2 \\
\hline $\begin{array}{l}\text { Extremely } \\
\text { unlikely } \\
<10^{-5}\end{array}$ & 3 & 3 & 3 & 3 \\
\hline & $\begin{array}{l}\text { lo } \\
\text { w }\end{array}$ & $\begin{array}{l}\text { Averag } \\
\text { e }\end{array}$ & $\begin{array}{l}\text { hig } \\
\mathrm{h}\end{array}$ & $\begin{array}{l}\text { Catastrophi } \\
\mathrm{c}\end{array}$ \\
\hline
\end{tabular}

The following table represents their risk levels.

Table 3 Evaluation of safety barriers.

\begin{tabular}{|l|l|}
\hline Scenarios & Risk level \\
\hline 1 & Acceptable \\
\hline 2 & Improvable \\
\hline 3 & Acceptable \\
\hline
\end{tabular}




\section{CONCLUSION}

Some important thing that should be mentioned in this paper that is the fired heater play a very inportant role in crude distillation unit and hence all the the refinery. The shut down of the heater means shut down of all the plant, bad operation in the heater means off spec products.

In this paper the ETA method is applied on the fired heater of ADRAR refinery to evaluate the safety barriers. The results show that the safety barriers recommended by the HAZOP study are sufficient to reduce the risk level.

\section{References}

[1] Sohag Kabir , Yiannis Papadopoulos , "A review of applications of fuzzy sets to safety and reliability engineering," International journal of Approximate Reasoning 100(2018) 29-55.

[2] M.H. Chun, K.I.AHN," Assessment of the potential applicatbility of fuzzy set theory to accident progression event trees with phenomenological uncertainties", Reliab. Eng. Sys. Saf. 37(3) (1992) 237-252. [3] J.D.Andrews, S.J.Dunnett, "Event tree diagrams,"IEEE Trank.Riliab.49 (2) (2000) 230-238.

[4] David Huang, Toly Chen, Mao-Jiun J.Wang , "Afuzzy set approach for event tree analysis," Fuzzy sets and systems 118(2001) 153-165.
[5] Rasool Kenarangui, "Event tree analysis by fuzzy probability", IEE transactions on reliability , Vol.40, No 1.1991April.

[6] Dr.Arshad Ahmad, university teknologi Malaysia, cours,event tree analysis, email: arshad@utm.my

[7] Marvin Rausand, Arnljot Hoyland,"System Reliability Theory Models, Statistical Methods, and Applications", Wiley,2004.

[8] Nigel Hyatt, "Guidelines for process hazards analysis, hazards identification and risk analysis", $1^{\text {st }}$ Edition, 8 printing- March 2004.

[9] Trevor Kletz, " HAZOP and HAZAN: identifying and assessing process industry hazards", fourth edition.

[10] David Macdonald, BSc(Hons) Inst.Eng.Senior Engineer, IDC Technologies, cape town, South africa, " Practical Hazops, Trips and alarms", series editor: steve mackay.

[11] Dennis P.Nolan,PH.D,P.E, "Safety and Security review for the Process industries, application of HAZOP, PHA, What-If and SVA rewiews, $4^{\text {th }}$ edition.

[12] Dr.Sam Mannan, PE, CSP, “Lee's loss prevention in the process industries: Hazard identification, $3^{\text {rd }}$ edition.

[13] B.Debray, S.Chaumette, S.Descouriere, V.Trommeter," Méthodes d'analyse des risques générés par une installation industrielle", Ministère de l'Ecologie et du développement durable.

[14] Apprendix c PFD values.

[15] Marszal, Edward M, Eric W, "Systemetic Methods including Layer of Protection Analysis", 2002 ISA - The instrumentation, systems, and automation society. 